\title{
Cross linking of collagen is increased in colonic diverticulosis
}

\author{
L Wess, M A Eastwood, T J Wess, A Busuttil, A Miller
}

\begin{abstract}
Development of colonic diverticulosis is a function of age and declining colonic wall mechanical strength. The latter is partly a consequence of changes in the collagen structure. Collagen from unaffected human colons $(n=20$, age range $20-80$ years) and those with colonic diverticulosis ( $n=5$, age range 67-80 years) were obtained at necropsy. The total collagen content was measured as the hydroxyproline content and cross linkage by collagen solubility in weak acid was studied. The colonic total collagen content was constant with age (mean (SD) $15.8(0.3)$ $\mathrm{mg} / 100 \mathrm{mg}$ wet weight of tissue). The acid solubility of the collagen, however, increased after the age of $\mathbf{4 0}$ years: at over 60 years, colonic diverticulosis was associated with an increased acid solubility ratio compared with values in unaffected colons (15.3 (0.2); compared with $9.2(0.2)$, $\mathbf{p}<0 \cdot 001)$. The cross linking of colonic collagen increases with age. These changes seem to be a factor in the aetiology of colonic diverticulosis.

(Gut 1995; 37: 91-94)
\end{abstract}

Keywords: colonic diverticulosis, collagen content.

Collagen is the most abundant protein in mammals and serves to maintain the structural integrity of tissues. The submucosa of the large bowel is composed almost exclusively of collagen fibrils, ${ }^{1}$ and as such is the layer which plays an important role in maintaining the integrity and viscoelastic properties of the colonic wall. The mechanical properties of the colonic wall depend on the individual components, and their juxtaposition and interaction. The viscoelastic properties of collagen and elastin give the colon its expandability and strength, and maintain its shape. These aspects of its intrinsic physical strength are, however, known to deteriorate with advancing age. ${ }^{23}$

Colonic diverticulosis is an increasingly common condition in western populations, and is always more pronounced in the sigmoid colon. It is a rare disorder before the age of 30 , yet a third of the population have diverticulosis by the sixth decade and a half by the ninth decade. ${ }^{4}$ Painter believed that the high incidence of this disease results from a decline in the consumption of dietary fibre. ${ }^{5}$ The age related pathological changes in the colonic wall may also develop as a feature of the aging process and could be secondary to a decline in the structural and mechanical integrity of the various layers on the large bowel wall. ${ }^{2}$
Structural changes which occur with advancing age include thickening of the circular and longitudinal muscle coats, and a progressive increase in the thickness of the individual connective tissue components of the colonic wall, such as collagen and elastin. ${ }^{2}$

Collagen is known to have intermolecular and intramolecular cross links which stabilise and give strength to the tissue in which it is located. Cross linkage in collagen is based on aldehyde formation from lysine or hydroxylysine residues. By stabilising the molecular arrangement within collagen fibrils, intermolecular cross links confer stability to the collagen containing tissue. ${ }^{6-8}$

Collagen solubility in weak acids is indirectly related to the degree of cross linkage in the collagen of the tissue under study: a higher solubility index indicates a higher degree of cross linkage of the collagen molecules. ${ }^{67}$

The ratio of insoluble to soluble collagen (the solubility index) gives an indication of the amount and possibly the nature of the cross links present. Acid soluble collagen contains aldimine cross links $\left(-\mathrm{CH}_{2}-\mathrm{CN}=\mathrm{N}-\right)$. Acid insoluble collagen contains ketoimine cross links (- $\mathrm{CO}-\mathrm{CH}_{2}-\mathrm{NA}-$ ) and mature cross links of both the allysine and hydroxyallysine pathways. Cross links resulting from the Maillard reaction may also be present in the insoluble fraction. ${ }^{7}$ The measurement of collagen solubility gives an indirect, inverse measure of the amounts of cross links as these are insoluble in weak acids. The insoluble residue can be regarded as the result of ketoimine cross links, mature cross links of both the allysine and hydroxyallysine pathways and advanced glycation products. ${ }^{7}$ Accumulation of covalently linked sugar molecules and related increased cross linking products are found on a variety of molecules with aging. The acid solubility of collagen in some tissues, such as skin, vascular adventitia and the chordae tendinae of heart valves is known to be reduced with advancing age, ${ }^{8}$ and this finding provides the basis for our study.

\section{Methods}

Colonic specimens were obtained from the necropsy suite at the Western General Hospital, Edinburgh. Specimens from subjects ranging in age from 20 to 80 years were studied: they had been obtained within one hour of beginning the necropsy. None of the subjects had died from or were known to have suffered from primary colonic disease. The bodies had all been stored at $4^{\circ} \mathrm{C}$ before necropsy, which was conducted by a consultant pathologist $(\mathrm{AB})$. 
TABLE I Total collagen content expressed as $m g / 100 \mathrm{mg}$ wet weight tissue from the four regions of the colon. Results are expressed as mean (SD)

\begin{tabular}{|c|c|c|c|c|c|}
\hline \multirow[b]{2}{*}{ Site } & \multirow{2}{*}{$\begin{array}{l}\text { Normal, } \\
<60 y \\
(n=11)\end{array}$} & \multirow{2}{*}{$\begin{array}{l}\text { Normal, } \\
>60 y \\
(n=9)\end{array}$} & \multirow[b]{2}{*}{$\begin{array}{l}\text { Diverticulosis } \\
(n=5)\end{array}$} & \multicolumn{2}{|l|}{ p Value } \\
\hline & & & & $\begin{array}{l}\text { Effect of } \\
\text { diverticulosis }\end{array}$ & $\begin{array}{l}\text { Correlation } \\
\text { with aget }\end{array}$ \\
\hline Ascending & $15 \cdot 1(0.58)$ & $15.5(0.41)$ & $15.5(0.32)$ & NS & NS \\
\hline Transverse & $15 \cdot 2(0.40)$ & $15.6(0.27)$ & $15 \cdot 5(0 \cdot 26)$ & NS & NS \\
\hline Descending & $15.3(0.60)$ & $15 \cdot 3(0.56)$ & $15 \cdot 5(0 \cdot 29)$ & NS & NS \\
\hline Sigmoid & $15.0(0.50)$ & $15 \cdot 6(0.48)$ & $15 \cdot 7(0 \cdot 24)$ & NS & NS \\
\hline
\end{tabular}

${ }^{\star} \mathrm{p}$ Value for the effect of diverticulosis in subjects over 60 years using analysis of covariance. $t p$ Value for the effect of age between those under 60 and over 60 years using analysis of covariance.
TOTAL COLLAGEN CONTENT AND THE SOLUBILITY INDEX

The sections were washed in mammalian Ringer solution, and $1 \mathrm{~g}$ portions were homogenised and extracted for 48 hours in 10 $\mathrm{ml} 0.5 \mathrm{M}$ acetic acid (1 ml/100 mg tissue) at $4^{\circ} \mathrm{C}$ to extract the acid soluble collagen. After incubation, the resulting homogenate was centrifuged at $37000 \mathrm{rpm}$ for one hour, and the pellet and supernatant were removed and stored separately. This fraction was termed acid soluble collagen. The pellet fraction was hydrolysed at $110^{\circ} \mathrm{C}$ with $6 \mathrm{~N} \mathrm{HCl}$ for 24 h. $^{8}$ The acid was evaporated off in a rotary evaporator, weighed, and then reconstituted in $0.5 \mathrm{M}$ acetic acid $(1 \mathrm{ml} / 100 \mathrm{mg}$ ) for analysis of the hydroxyproline content. This fraction was termed acid insoluble collagen. Both the supernatant and the pellet were analysed for hydroxyproline content using the method of Kivirikko et al. ${ }^{9}$ The collagen hydroxyproline content was measured as this is the most abundant imino acid in collagen and, as such, is the best measure of the collagen content. ${ }^{10}$ The total collagen content of the original tissues (mg/100 mg wet weight) was calculated by the addition of the values for acid soluble and acid insoluble fractions. The ratio of insoluble collagen to soluble collagen (the solubility index) gives an indirect measure of the degree of cross linkage. The mean of the three determinations of the solubility index were used for calculating the median and means of each tissue sample within the groups.

This procedure was applied to all regions of the colon in each of the 25 subjects.
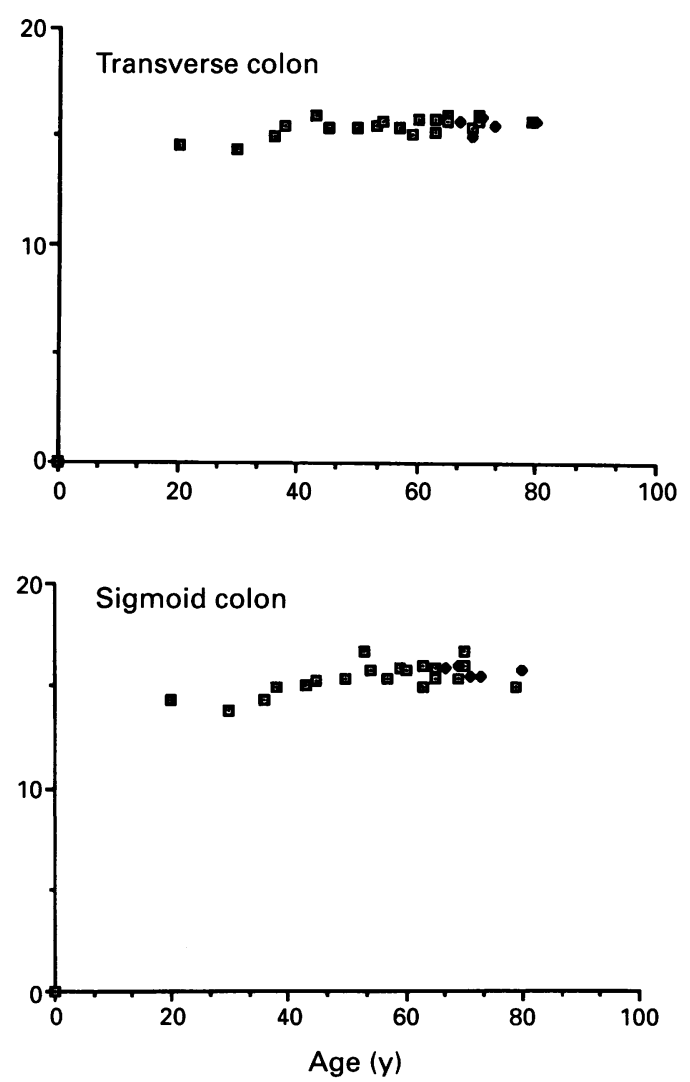

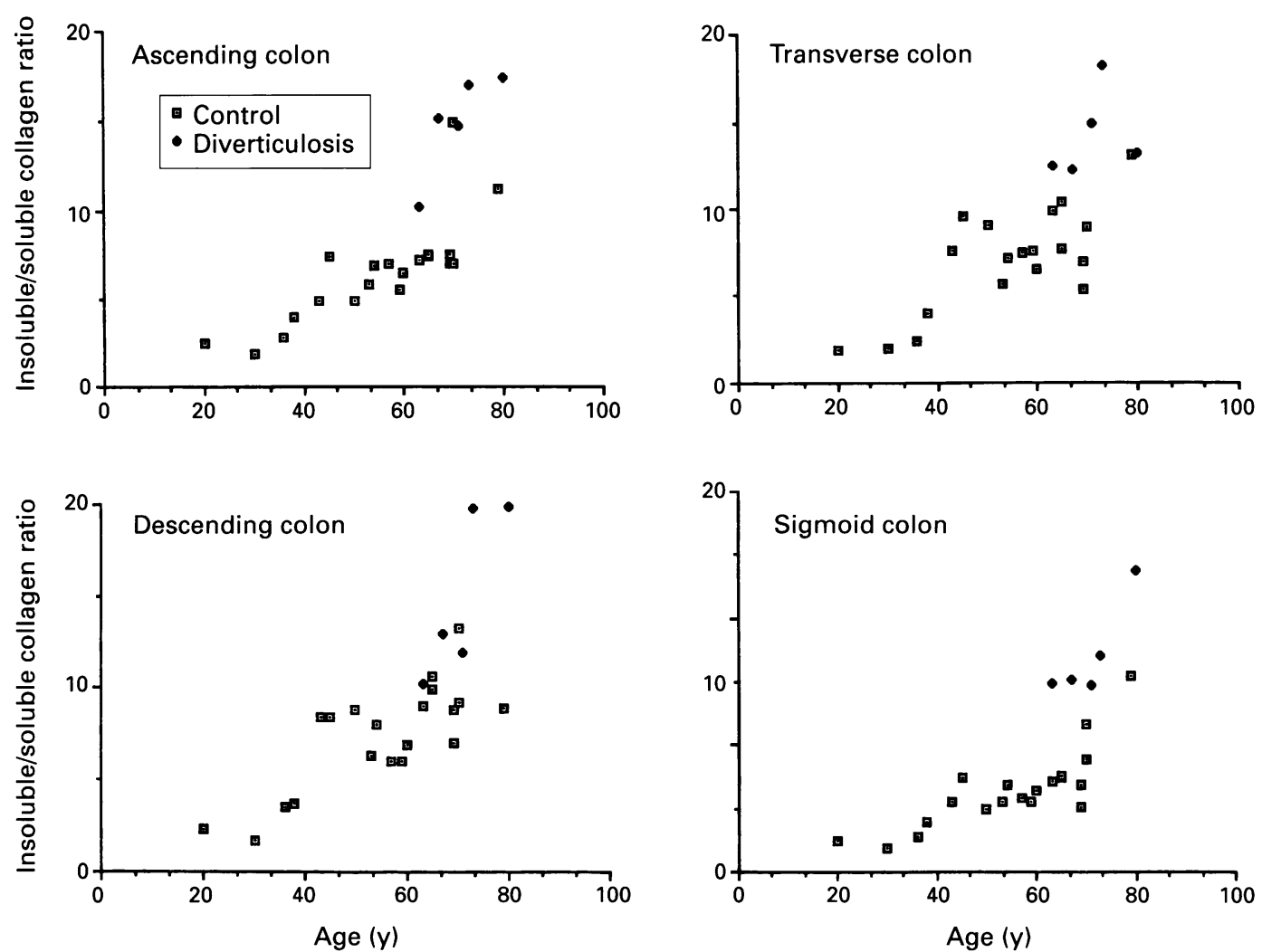

Figure 2: Results of the measurement of the acid solubility of collagen of the four regions of the human colon in normal healthy colons and those affected by colonic diverticulosis. The results are expressed as a ratio of insoluble:soluble collagen as found in the colon wall and are plotted against the age of the subject.

Analysis of covariance was used to analyse the results in three groups - normal subjects under 60 years, normal subjects over 60 years, and subjects over 60 with diverticulosis.

\section{Results}

The total collagen results are shown in Table I. The overall mean (SD) total collagen content was $15.8(0.3) \mathrm{mg} / 100 \mathrm{mg}$ wet weight. The total collagen content of the large bowel wall was not found to be altered according to the colonic site from which the sample had been collected, or the age of the subject, or the presence of colonic diverticulosis (Fig 1, Table I).

There is, however, a steady increase in the proportion of insoluble collagen with advancing age, especially after the age of 40 years (Fig 2 ). The mean (SD) values of the solubility index for control subjects under 60 years, control subjects over 60 years, and subjects with diverticulosis are shown in Table II and Figure 2. The mean (SD) acid solubility index for all of the colon sites in subjects with

TABLE II Acid solubility ratio expressed as insoluble collagen:soluble collagen from the four regions of the colon. Results are expressed as mean (SD)

\begin{tabular}{|c|c|c|c|c|c|}
\hline \multirow[b]{2}{*}{ Site } & \multirow{2}{*}{$\begin{array}{l}\text { Normal, } \\
<60 y \\
(n=11)\end{array}$} & \multirow{2}{*}{$\begin{array}{l}\text { Normal, } \\
>60 y \\
(n=9)\end{array}$} & \multirow[b]{2}{*}{$\begin{array}{l}\text { Diverticulosis } \\
(n=5)\end{array}$} & \multicolumn{2}{|l|}{ p Value } \\
\hline & & & & $\begin{array}{l}\text { Effect of } \\
\text { diverticulosis }\end{array}$ & $\begin{array}{l}\text { Correlation } \\
\text { with age }\end{array}$ \\
\hline $\begin{array}{l}\text { Ascending } \\
\text { Transverse } \\
\text { Descending } \\
\text { Sigmoid }\end{array}$ & $\begin{array}{l}4 \cdot 85(1 \cdot 2) \\
5 \cdot 86(1 \cdot 6) \\
5 \cdot 74(1 \cdot 8) \\
5 \cdot 40(1 \cdot 7)\end{array}$ & $\begin{array}{r}8.43(1.6) \\
8.65(2.0) \\
9.40(1.9) \\
10.30(2.5)\end{array}$ & $\begin{array}{l}14 \cdot 9(2 \cdot 1) \\
14 \cdot 24(2 \cdot 0) \\
15 \cdot 0(2 \cdot 3) \\
17 \cdot 1(2 \cdot 8)\end{array}$ & $\begin{array}{l}<0.01 \\
<0.01 \\
<0.001 \\
<0.001\end{array}$ & $\begin{array}{l}<0.001 \\
<0.001 \\
<0.01 \\
<0.001\end{array}$ \\
\hline
\end{tabular}

${ }^{\star} p$ Value for the effect of diverticulosis in subjects over 60 years using analysis of covariance. tp Value for the effect of age between those under 60 and over 60 years using analysis of covariance. diverticulosis was $15 \cdot 3(0 \cdot 2)$. Values for normal subjects aged over 60 years and under 60 years were respectively $9 \cdot 2(0.2)(p<0.001)$ and $5.5(1.5) \quad(\mathrm{p}<0.001)$ using analysis of covariance.

An important concern is whether autolysis might influence the results, especially with relation to cross linkage. All of the results (collagen and solubility ratio) from all tissues were plotted against time from death to necropsy. No influence of time after death on the results could be seen in those under or over 60 years and with or without diverticulosis.

\section{Discussion}

The normal healthy colon has both propulsive and storage functions, and as such needs to be able to withstand the extremes of pressure in the large bowel - equivalent to $100-150 \mathrm{~mm}$ Hg. ${ }^{11}$ The intrinsic strength of the bowel wall is thought to be invested in the submucosal layer.

The colonic wall is known to be affected by the aging process in a variety of ways: there is appreciable muscle thickening and an increase in the amount of elastin present in the tissues. ${ }^{5}$ Noticeable muscular thickening is also a feature of colonic diverticulosis. Despite this increased thickness of muscle coats, however, the colonic wall is reported to have a lowered resistance to distension in diverticulosis. ${ }^{2}$

Collagen in the colon is largely located in the submucosal layer, thus making this the most important layer for structural integrity: Watters et $a l^{2}$ showed that both the tensile strength and the 'burst strength' of the human colonic wall depend on the integrity of the submucosa. 
Thomson et al 1213 showed that colonic submucosal structure changes with age in both normal colons and in those showing diverticulosis. These changes include differences between the right and left sides of the colon differences in the form of an increase in the number of fibrils and a decrease in the fibril diameter in left colon compared with the right. The ultrastructural studies also indicate the intactness of the submucosa after isolation and clamping.

The hydroxyproline measurements enabled a determination of the total collagen content of the colon and also the amount of collagen in the soluble and insoluble phases after weak acid extraction. ${ }^{9}$ The amounts of reducible and acid labile cross links in collagen decrease with the maturation of a tissue, ${ }^{7}$ But these changes in collagen cross links are complex. Collagen solubility is related to the degree of cross linkage in the collagen of the tissue: a higher solubility index indicates a higher degree of cross linkage of the collagen molecules. ${ }^{7}$

Collagen molecules aggregate in a highly specific manner to form precipitated fibrils which provide a substrate for the enzyme lysyl oxidase (protein lysine 6-oxidase, E.C. 1.2.3.13). The enzyme acts on specific lysine and hydroxylysine residues at $\epsilon$-amino group. The oxidative deamination of these residues produces aldehydes. The reaction between two allysine residues results in the formation of an allysine aldol cross link, which is the intramolecular type of cross linkage within a collagen structure. ${ }^{6}$

It has been proposed that sugar molecules may have a role in the aging process. Accumulation of covalently linked sugar molecules and related cross linking products is found on a variety of molecules with aging. ${ }^{8}$ Reduced solubility of collagen with age could be related to the accumulation of glycation products in a tissue. Molecules such as collagen have been shown to contain nonenzymatically attached sugar molecules.

If the degree of collagen cross linkage increases, the resultant tissue becomes more rigid. ${ }^{14}$ The ratio of insoluble to soluble collagen, and hence the inferred level of mature and age related cross linked collagen, is shown in this study to be significantly different between healthy colons from subjects over 60 years and colons from subject of the same age showing diverticulosis. These findings were not an artefact of autolysis after death.

We have produced evidence that colonic diverticular develop as a consequence of structural changes akin to those of aging. In all four sections of the colon, none of the results for total collagen content measurement were affected by aging of the tissue, but collagen solubility measurements showed pronounced differences with a significant relation between the acid solubility of collagen and the age of the human subject $(p<0.001)$. Acid insolubility increases after the age of 40 years - an interesting finding as colonic diverticulosis is rare before that age. This relationship was more strongly significant in the sigmoid colon, which is the predominant location for the development of colonic diverticula.

These results also indicate, that colonic collagen from subjects affected by colonic diverticulosis is less acid soluble than that from healthy colons of those over 60 years $(p<0 \cdot 05)$. This suggests that the collagen from colonic diverticulosis colons has a higher number of cross links than unaffected colonic tissue.

This study illustrates that the structural changes to the collagen of tissues affected by colonic diverticulosis are similar to those that occur as part of the aging process but are greater than could be ascribed to aging alone. We therefore suggest that colonic diverticulosis is the consequence of exaggerated and premature aging process and is related to intrinsic changes in collagen. The relationship between these changes and dietary habits, racial groups, and other life events must still be speculative.

1 Lord MG, Valies O. A morphologic study of the submucosa of the large intestine. Surg Gynecol Obstet 1977; 145: 55-60.

2 Watters DAK, Smith AN, Eastwood MA. Mechanical properties of the colon; comparison of the features of the African and European colon in vitro. Gut 1985; 26: African

3 Whyteway J, Morson DC. Pathology of the aging-diverticular disease. Clinics in Gastroenterology 1985; 14: 829-46.

4 Morson DC, Dawson IMP. In: Gastrointestinal pathology. Oxford: Blackwell Scientific Publications, 1972.

5 Painter NS. Diverticular disease of the colon. London: William Heinemann Medical Books, 1975.

6 Bornstein P, Piez KA. The nature of the intramolecular crosslinks in collagen. The separation and characterisation of peptides from the crosslink region of rat skin collagen. Biochemistry 1966; 5: 3460-73.

7 Robins SP, Shimokomaki M, Bailey AJ. The chemistry of the collagen crosslinks. Age related changes in the reducible components of intact bovine collagen fibres. reducible components of intact

8 Robins SP, Bailey AJ. Age related changes in collagen. The identification of reducible lysine carbohydrate condensation products. Biochem Biophys Res Commun 1972; 48: 76-84.

9 Kivirikko KI, Laitinen O, Prockup DJ. Modifications of a specific assay for hydroxyproline in urine. Anal Biochem 1967; 19: 249-55.

10 Chang K, Uitto J, Rowold EA, Grant GA, Kilo C, Williamson JR. Increased collagen crosslinkages in experimental diabetes. Reversal by $\beta$-aminopropionitrile and D-penicillamine. Diabetes 1980; 29: 778-81.

11 Fry RD, Shemesh EL. Perforation of the rectum and sigmoid colon during barium-enema examination. Management and prevention. Dis Colon Rectum 1989; 32: 759-64.

12 Thomson HJ, Busuttil A, Eastwood MA, Smith AN, Elton RA. Submucosal collagen changes in the normal colon and in diverticular disease. Int $\mathcal{F}$ Colorect Dis 1987; 2: 208-13.

13 Thomson JH, Busuttil A, Eastwood MA, Smith AN, Elton RA. The submucosa of the human colon. Fournal of Ultrastructural Research 1987; 96: 22-30.

14 Schnider SL, Kohn RR. Effects of age and diabetes mellitus on the solubility of collagen from human skin, tracheal cartilage and dura mater. Exp Gerontol 1982; 17: 185-94.

15 Eyre DR, Paz MA, Gallup PM. Cross-linking in collagen and elastin. Annu Rev Biochem 1984; 53: 717-48. 